\title{
QUEEN'S
UNIVERSITY
BELFAST
}

\section{Liquid Crystal Based Beam Scanning Reflectarrays and Their Potential in SATCOM Antennas}

Perez-Palomino, G., Barba, M., Encinar, J., Cahill, R., Dickie, R., \& Baine, P. (2017). Liquid Crystal Based Beam Scanning Reflectarrays and Their Potential in SATCOM Antennas. In Proceedings of EuCAP 2017 (pp. 34283431). Institute of Electrical and Electronics Engineers Inc..

\section{Published in:}

Proceedings of EuCAP 2017

\section{Document Version:}

Peer reviewed version

Queen's University Belfast - Research Portal:

Link to publication record in Queen's University Belfast Research Portal

\section{Publisher rights}

( 2017 IEEE. Personal use of this material is permitted. This work is made available online in accordance with the publisher's policies. Please refer to any applicable terms of use of the publisher.

\section{General rights}

Copyright for the publications made accessible via the Queen's University Belfast Research Portal is retained by the author(s) and / or other copyright owners and it is a condition of accessing these publications that users recognise and abide by the legal requirements associated with these rights.

Take down policy

The Research Portal is Queen's institutional repository that provides access to Queen's research output. Every effort has been made to ensure that content in the Research Portal does not infringe any person's rights, or applicable UK laws. If you discover content in the Research Portal that you believe breaches copyright or violates any law, please contact openaccess@qub.ac.uk. 


\title{
Liquid Crystal Based Beam Scanning Reflectarrays and Their Potential in SATCOM Antennas
}

\author{
G. Perez-Palomino ${ }^{1}$, M. Barba ${ }^{1}$, J.A. Encinar ${ }^{1}$, R. Cahill ${ }^{2}$, R. Dickie ${ }^{2}$ and P. Baine ${ }^{2}$ \\ ${ }^{1}$ Signals, Systems and Radiocomm. Dept., Technical University of Madrid, Spain, e-mail: \{gperez, mbarba,Encinar\}@etc.upm.es \\ ${ }^{2}$ ECIT, Queen's University Belfast, Northern Ireland, UK, e-mail: \{r.cahill, r.dickie, p.baine $\} @ e e . q u b . a c . u k$
}

\begin{abstract}
This paper presents recent developments in Liquid Crystal-based reflectarray antennas for mm-wave applications, future perspectives for this technology and its particular use in SATCOM applications.
\end{abstract}

Index Terms-electronically reconfigurable reflectarray, Liquid Cystals (LCs), SATCOM antennas.

\section{INTRODUCTION}

LC-based reflectarray antennas are a very attractive option to produce low-cost and high-gain electronically reconfigurable antennas at $\mathrm{mm}$ and sub-mm wave frequencies. The required phase agility is obtained by exploiting the property of the liquid crystals to change its permittivity by the application of an AC voltage [1]-[4]. This property is exhibited over a wide range of frequencies, spanning AC to optical wavelengths. The basic LC-based reflectarray cell is constructed of a superstrate on which the metalized elements are printed, a ground plane, and a cavity that is filled with the LC (Fig. 1). If the permittivity is varied, both the resonance frequency of the metallic patches and the phase of the reflected field are changed. Since the permittivity of the LC can be varied locally, the tunable material can be integrated in all the cells at the same time during the fabrication process, so that the reconfigurable antenna can be manufactured without the need for integrating hundreds or thousands devices in the array. Thus, the fabrication process is significantly simplified, which is especially beneficial for large reconfigurable arrays such as those required for SATCOM applications.

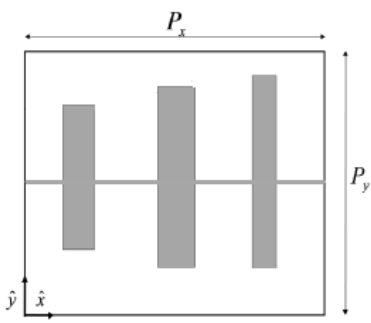

(a)

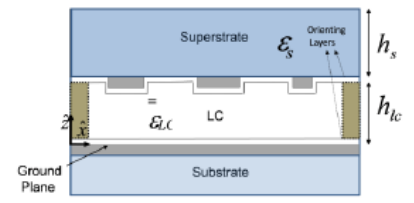

(b)
Fig. 1. Schematic view of a LC multi-resonant reflectarray unit cell based on three coplanar dipoles.(a) Top view and (b) lateral view.

\section{RECENT DEVELOPMENTS}

The functionality of LC-based reflectarrays was investigated in several references during the last decade. In [1]-[3], the behavior of a single resonant LC-reflectarray cell was experimentally demonstrated in $\mathrm{X}, \mathrm{Ka}$ and $\mathrm{W}$ bands, respectively. The previous work highlighted several limitations for this type of cell, such as: insufficient phase range, narrow bandwidth, high losses and often poor agreement between simulated and measured results. At antenna level, the structures exhibited low gain and efficiency, narrow band operation, high side-lobe levels (SLL), and a very small scan angle range.

These limitations were due to the single resonant performance of the cells and the use of simple models to describe the behavior of the LC and to obtain the required bias voltages. In many cases, the latter led to the generation of very large phase errors across the antenna aperture. More recent investigations described innovative work to overcome these limitations by including several coplanar resonators [4], and by introducing accurate modeling of the LC which enabled the required voltages to be obtained in conjunction with a much reduced phase error [5]. These improved design procedures were used to design an antenna and demonstrate beam scanning in one plane (linear polarization) at $100 \mathrm{GHz}$ [6]. Excellent results were obtained (see Fig. 2) and good agreement between simulations and measurements was observed. The electrical performance obtained in terms of bandwidth $(8 \%)$, SLL $(<-13 \mathrm{~dB})$, scan range $\left(60^{\circ}\right)$ and efficiency $(20 \%, 19.6 \mathrm{dBi}$ maximum gain) was significantly better than those presented previously even at lower frequencies. However, the antenna efficiency was lower than desirable, since the reflection phases of the LC-cells were only varied in 1-D, limiting the full focusing capabilities of the aperture.

The most recent work on LC-reflectarrays for beam scanning has investigated a means of increasing the antenna gain by mechanically collimating the beam in the orthogonal plane using an additional reflector. In [7], a reconfigurable folded reflectarray antenna configuration based on LC was experimentally demonstrated for beam scanning in one plane at $78 \mathrm{GHz}$. In this architecture, the LC-based reflectarray is employed as sub-reflector, and introduces a reconfigurable phase-shift to one polarization of the incident electric field but is transparent to the orthogonal field vector. The passive main reflectarray is designed to rotate the polarization and to focus the beam, so that the gain improvement is reported to 
be $6 \mathrm{~dB}$ with respect to a configuration which is provided by the same sub-reflector but with 1-D phase control. The electrical performance obtained in this case is: bandwidth $(<1 \%)$, SLL $(<-6 \mathrm{~dB})$, scanning range $\left(12^{\circ}\right)$ and a maximum gain $(25.1 \mathrm{dBi})$.

An additional improvement has been recently achieved by the authors of this paper by developing a dual-reflector antenna with a 1-D LC-reflectarray sub-reflector and a metal parabolic reflector. The structure was designed to work at a center frequency of $100 \mathrm{GHz}$. For this configuration, the antenna gain is increased as a consequence of the magnification factor (besides the aforementioned increase of $6 \mathrm{~dB}$ ), although at the expense of decreasing the scan range by the same factor. The measured electrical performance is summarized as: bandwidth $(7 \%)$, SLL $(<-15 \mathrm{~dB})$, beam scan range $\left(12^{\circ}\right)$ and maximum gain $(35.2 \mathrm{dBi})$. The results will be shown in the final presentation. Other dual-reflector architectures are being investigated at present in order to obtain a trade-off between gain and scan range [8].

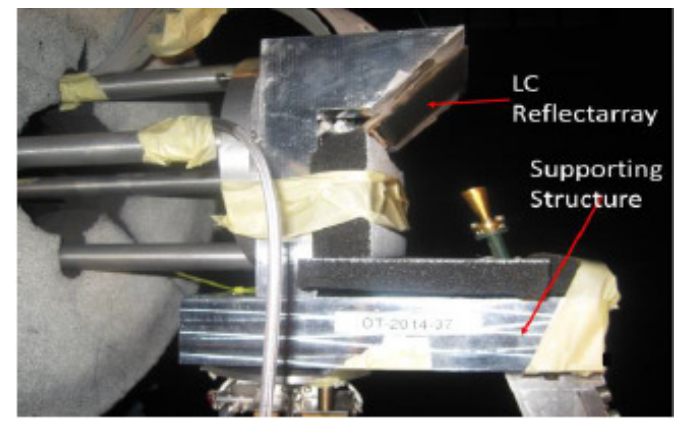

(a)

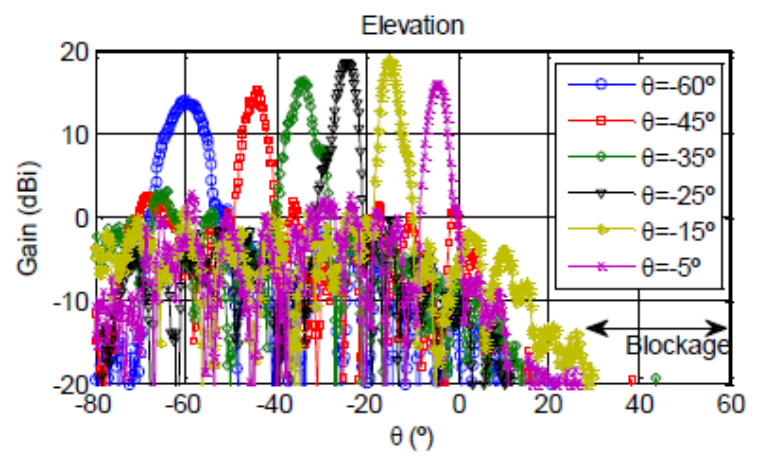

(b)

Fig. 2. (a) Photograph and (b) Measured elevation radiation patterns at $100 \mathrm{GHz}$ for several scan angles, of the single offset LC based reflectarray antenna designed and tested at $100 \mathrm{GHz}$ in [6].

\section{FUTURE PERSPECTIVES FOR SATCOM ANTENNAS}

All concepts, models, architectures and procedures described above are usable in a relatively wide range of wavelengths, including SATCOM frequencies. Although major advances over the past decade have led to significant improvements in the electrical performance of LCreflectarray antennas, a few technical challenges remain to be solved before commercial exploitation is possible. One of the most important features that has yet to be achieved is full electronic beam scanning capability (or electronic beam shaping), which requires $2-\mathrm{D}$ addressing of the voltage to be implemented in the LC-cells. It is noted that although independent control of the phase-shift in each cell can more easily be obtained using LC technology compared to other options such as MEMS or diodes (see Fig. 3a), LC material exhibits an additional property that allows passive addressing of the voltage [9].

The advantage of passive addressing lies in the fact that it just needs a segmented ground plane (see Fig. 3b), which drastically reduces the complexity of the 2-D addressing, and allows the creation of electrically large and low cost reconfigurable-beam antennas. In the final presentation, recent results obtained by the authors related to 2-D electronically reconfigurable reflectarrays based on LC will be shown.

Another parameter that needs to be improved in this type of beam-scanning antennas is the efficiency. Commercially available LC mixtures are engineered for operation at microwave frequencies and therefore exhibit best performance (losses and tunability) at frequencies typically within X-band or Ka-band. This fact together with the inherent reduction in metal losses, suggest that LC reflectarray antennas will exhibit higher efficiencies (20$40 \%$ ) at SATCOM frequencies than at $100 \mathrm{GHz}$. In addition, the use of new LC mixtures and/or more complex unit cells architectures are being investigated with the aim of increasing the antenna efficiency.

The beam scan speed of the LC reflectarray, which directly depends on the LC thickness and the viscosity, is another parameter that requires improvement to meet the requirements for some applications. The LC thicknesses used to create electronically tunable antennas operating at frequencies above $60 \mathrm{GHz}$ are usually thicker than $80 \mu \mathrm{m}$, and the switching times are around 1-2 seconds. To reduce this, the use of polymer networks mixed with LCs (PNLCs) is being investigated by the authors of the paper, together with new cell architectures that are able to reduce the LC thickness without compromising electrical performance. PNLCs have been demonstrated to be capable of reducing the switching times several orders of magnitude for arbitrary thicknesses in optics [10], and therefore this approach opens the possibility of developing LC reflectarrays at frequencies below $60 \mathrm{GHz}$. Note that the use of the reflectarray cells such as those reported in [4] implies a thicknesses of $200 \mu \mathrm{m}$ is required at SATCOM frequencies. 


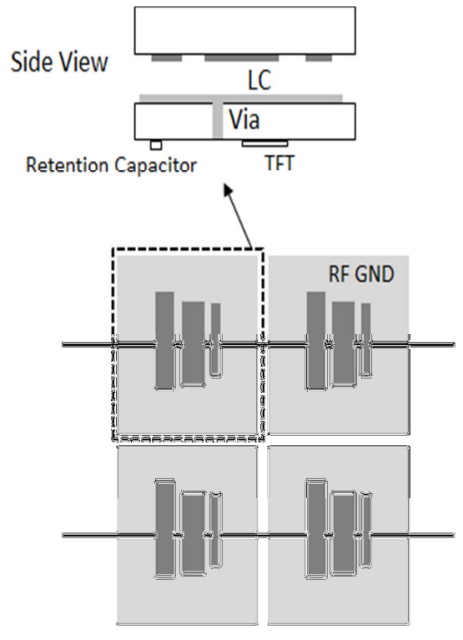

(a) (b)

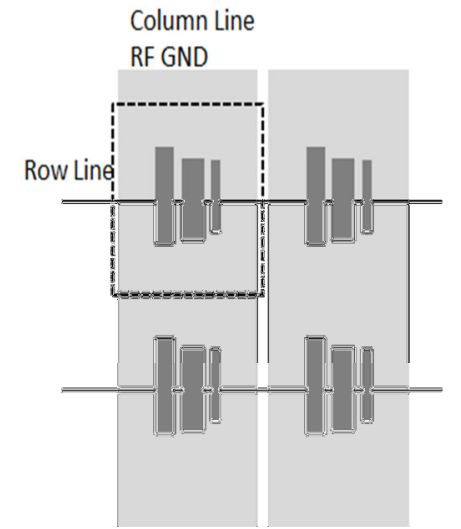

Fig. 3. (a) Active and (b) passive LC matrices to obtain a 2-D addressing of the voltage. Top view
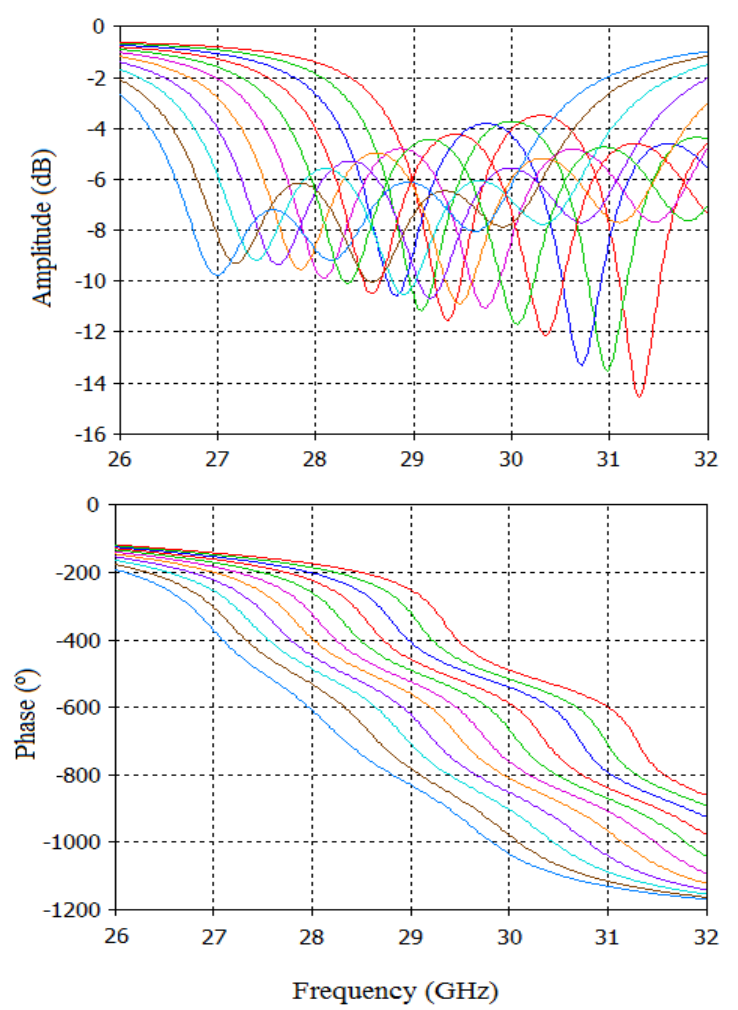

Fig. 4. Simulated reflection coefficient (amplitude and phase) of a multiresonant cell composed of five parallel dipoles designed to operate at $30 \mathrm{GHz}$ with improved phase-range. Each color represents a permittivity tensor of the GT3-23001 associated with voltages between $0 \mathrm{~V}$ and the saturation $(15 \mathrm{Vrms})$.

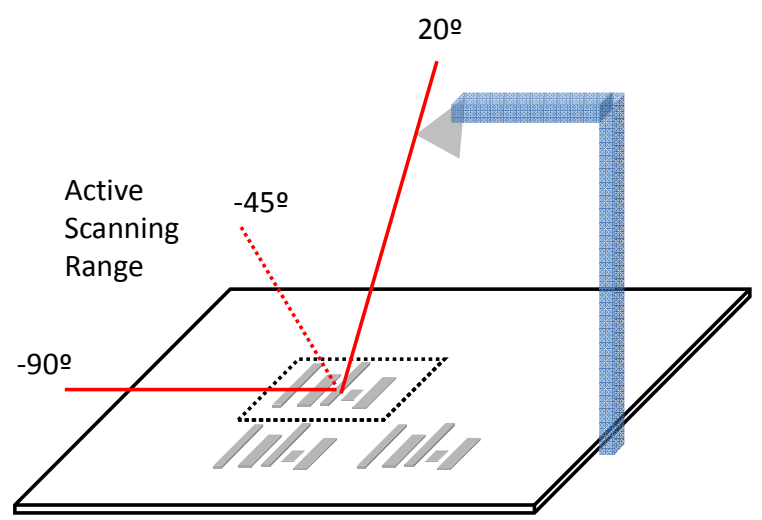

Fig. 5. Schematic of the LC-reflectarray

As was noted above, investigations to create new cell architectures are necessary to improve in part some of the most important features of the antenna. As an example, Fig. 4 shows preliminary computed results of amplitude and phase of the reflection coefficient versus frequency for several permittivity tensors [5] of a multi-resonant cell (size $\mathrm{P}_{\mathrm{x}}=5 \mathrm{~mm}$ and $\mathrm{P}_{\mathrm{y}}=4.4 \mathrm{~mm}$ ) composed of five unequal length dipoles, that operates in Ka-band and uses commercially available LC GT3-23001 (used at $100 \mathrm{GHz}$ in [4]-[7]). A phase range of $600^{\circ}$ is achieved within a bandwidth of $10 \%$ that covers the uplink band of SATCOM (from $27.5 \mathrm{GHz}$ to $31 \mathrm{GHz}$ ). The phase-range is significantly larger than those achieved in the literature. The average reflection losses $(6$ $\mathrm{dB}$ ) are lower than those reported at $100 \mathrm{GHz}$, whereas that the LC thickness $(100 \mu \mathrm{m})$ is maintained similar to that one used at these frequencies. It should be highlighted that it is possible to trade-off a reduction in the loss with a reduction in the phase-range.

The cell has been designed by considering 1-mm thick low-cost FR-4 superstrate $\left(\varepsilon_{\mathrm{r}}=4, \tan \delta=0.01\right)$. Note that quartz or glass wafers are used at frequencies beyond $60 \mathrm{GHz}$ in order to reduce as much as possible the losses introduced by the superstrate and to maintain the appropriate thickness tolerances, although at the expense of assuming a relatively high cost. The main drawback in using FR-4 has to do with the fact that its surface is rough, so the polymer rubbing may not be possible to do. However, this cell exhibits enough phase-range to prevent the use of orienting layers, which simplifies the fabrication.

Using the results of the cell of Fig. 4, a preliminary design has been carried out for a LC-based reflectarray antenna operating at $30 \mathrm{GHz}$ for uplink SATCOM applications (assuming linear polarization). The antenna is composed by $70 \times 80$ cells $(350 \times 350 \mathrm{~mm})$, and the feed horn has been positioned so that the active scanning range ( 3 $\mathrm{dB}$ gain criteria) is between $\left(-45^{\circ}\right.$ and $\left.+20^{\circ}\right)$, as shown in Fig. 5. Fig. 6 shows the gain radiation patterns (elevation plane) calculated at $30 \mathrm{GHz}$ for several scan angles in the elevation plane. The numerical model simulates the real effects of the LC on the reflectarray surface [6] and assumes that a real feed horn illuminates the antenna. 


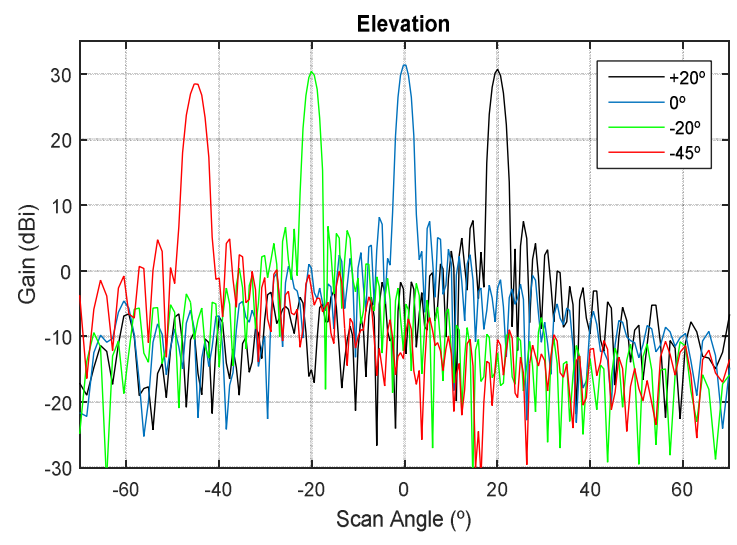

Fig. 6. Simulated co-polar gain radiation patterns (elevation plane) at 30 $\mathrm{GHz}$ for several scanning angles in the elevation plane

As can be noted, the maximum gain is $32.1 \mathrm{dBi}$ and the SLL is maintained lower than $-20 \mathrm{~dB}$ at all scan angles. The computed directivity is $38.3 \mathrm{dBi}$, so the average loss at cell level is $6.2 \mathrm{~dB}$, giving an efficiency of $25 \%$. Two antennas can be used to cover both links, so a similar procedure can be made to design the downlink antenna at $20 \mathrm{GHz}$.

In the final presentation, more details about novel cells, antenna architectures, materials and design procedures, which are considered by the authors to improve the performance of LC reflectarray antenna in terms of efficiency, scan speed, ease of fabrication, or even to achieve other required features for SATCOM antennas (circular polarization, dual-band, etc), will be discussed.

\section{CONCLUSIONS}

LC-based reflectarrays is a suitable candidate for developing low cost and high-gain electronic beamscanning antennas that can be designed to meet the challenging electrical requirements for typical SATCOM applications. Simple biasing arrangements and feed architectures in conjunction with fabrication processes suitable for mass production make this class of antenna an attractive option for commercial exploitation.

\section{ACKNOWLEDGMENT}

This work has been supported by the Spanish Ministry of Economy and Competitiveness under the project TEC201343345-P, the Regional Government of Madrid under project SPADERADAR-CM (P2013/ICE-3000) and the European Space Agency under project grant A0/1-6169/09/NL/JD.

\section{REFERENCES}

[1] W. Hu, M. Y. Ismail, R. Cahill, J. A. Encinar, V. Fusco, H. Gamble, D. Linton, R. Dickie, N. Grant, and S.P. Rea "Liquid-crystal-based reflectarray antenna with electronically switchable monopulse patterns," IEE Electronics Letters., vol. 43, no. 14, pp. 744-745, 2007
[2] A. Moessinger, et al., "Electronically reconfigurable reflectarrays with nematic liquid crystals," Electronics, Letters., vol. 42, no. 16, pp. 899-900, 2006.

[3] S. Bildik, et al., "Reconfigurable Liquid Crystal Reflectarray with Extended Tunable Phase Range" in Proc. 8th EuRAD, Manchester, Oct. 2011

[4] G. Perez-Palomino, et al., "Design and Experimental Validation of Liquid Crystal-Based Reconfigurable Reflectarray Elements With Improved Bandwidth in F-Band," IEEE Trans. Antennas Propagat., vol. 61, no. 4, pp. 1704-1713, Apr. 2013.

[5] G. Perez-Palomino, et al., "Accurate and Efficient Modeling to Calculate the Voltage Dependence of Liquid Crystal Based Reflectarray Cells," IEEE Trans. Antennas Propagat., vol. 62, no. 5, pp. 2659-2668, May. 2014.

[6] G. Perez-Palomino, et al., "Design and Demonstration of an Electronically Scanned Reflectarray Antenna at $100 \mathrm{GHz}$ Using Multi-Resonant Cells Based on Liquid Crystals," IEEE Trans. Antennas Propagat., vol. 63, no. 8, pp. 2659-2668, Aug. 2015.

[7] S. Bildik, et al.,"Reconfigurable Folded Reflectarray Antenna Based Upon Liquid Crystal Technology," IEEE Trans. Antennas Propagat., vol. 63, no. 1, pp. 122-132, Jan. 2015

[8] A.Garcia-Pino, et al., "A confocal reflector for a reflectarray-based scanning system", in Proc. 10th EuCAP, Davos, Apr. 2016

[9] T. N. Ruckmongathan, Addressing Techniques of Liquid Crystal Displays. 1st ed. Willey, 2014.

[10] J. Sum, S-T. Wu, and H. Yashuhiro,"A low Voltage submillisecondresponse polymer network liquid crystal spatial light modulator," Appl. Phys. Lett. Vol. 104, no 2, p.p 23305-23305-5. Jan. 2014 